\title{
Estudo Comparativo de Amidos Termoplásticos Derivados do Milho com Diferentes Teores de Amilose
}

\author{
Elisângela Corradini, Celso Lotti, Eliton S. de Medeiros \\ Departamento de Engenharia de Materiais, UFSCar
}

Antonio J. F. Carvalho

Instituto de Física de São Carlos, USP

Antonio A. S. Curvelo

Instituto de Química de São Carlos, USP

\author{
Luiz H. C. Mattoso \\ Embrapa Instrumentação Agropecuária, São Carlos, SP
}

\begin{abstract}
Resumo:Amidos de milho contendo aproximadamente 72 e $100 \%$ de amilopectina foram convertidos em amidos termoplásticos por processamento em um misturador intensivo a $160^{\circ} \mathrm{C}$, usando glicerol como plastificante. Os amidos termoplásticos foram condicionados em ambiente de $53 \pm 2 \%$ u.r. e caracterizados por medidas de absorção de água, difração de raios X, ensaios mecânicos de tração e por análises dinâmico mecânicas (DMA). O amido com menor teor de amilopectina apresentou maior viscosidade durante o processamento, que foi atribuída à estrutura da amilose. Os amidos termoplásticos TPS1 (72\% de amilopectina) e TPS2 (100\% de amilopectina) não mostraram diferenças apreciáveis nas propriedades de absorção de água. Após duas semanas de armazenamento, o TPS1 apresentou estrutura semicristalina, enquanto o TPS2 apresentou estrutura totalmente amorfa. Após seis semanas ocorreu um aumento da cristalinidade do TPS1 e ocorreu a formação de estruturas cristalinas no TPS2. As propriedades mecânicas e dinâmico-mecânicas foram afetadas pela cristalinidade do amido que é função da razão amilose/amilopectina.
\end{abstract}

Palavras-chave: Amido termoplástico, amilose, amilopectina, propriedades mecânicas, DMA, difração de raios-X.

\section{Comparative Studies of Corn Thermoplastic Starches with Different Amylose Content}

Abstract: Corn starches with approximately $72 \%$ and $100 \%$ of amylopectin were processed in an intensive mixer connected to a torque rheometer in the presence of glycerol (plasticizer) at $160^{\circ} \mathrm{C}$. The thermoplastic starches were conditioned at $53 \pm 2 \%$ of relative humidity for two weeks and characterized by X-ray diffraction, tensile test and dynamical mechanical analysis (DMA). The starch with lower amylopectin content presented higher viscosity during the processing which was attributed to linear amylose chains. The thermoplastic starches TPS1 (72\% of amylopectin) and TPS2 (100\% of amylopectin) did not display significant differences in water absorption. After two weeks of aging, TPS1 exhibited semicrystalline structure, whereas TPS2 presented a amorphous structure. After six weeks, the crystallinity of TPS1 increased and some crystalline behavior could be detected in TPS2. The mechanical and dynamical mechanical properties were affected by starch crystallinity, which is a function of amylose/amylopectin ratio.

Keywords: Thermoplastic starch, amylose, amylopectin, mechanical properties, DMA, X-ray diffraction.

\section{Introdução}

O amido, além de ser empregado nas indústrias de alimentos, de cosméticos, farmacêutica, de papel e têxtil, vem sendo utilizado também como material termoplástico em aplicações tais como: embalagens, potes para plantio, pratos e talheres descartáveis ${ }^{[1,2]}$. O amido é uma alternativa viável para este fim, devido a sua biodegradabilidade, baixo custo e disponibilidade ${ }^{[3]}$.
O amido nativo ou natural, apresenta estrutura granular semicristalina. Os grânulos são constituídos por macromoléculas de amilose e amilopectina. A amilose consiste de cadeias lineares, com massa molar entre $10^{1}-10^{2} \mathrm{Kg} /$ mol, enquanto que a amilopectina possui estrutura ramificada, com massa molar entre $10^{4}-10^{6} \mathrm{Kg} / \mathrm{mol}^{[4,5]}$. Na Figura 1 estão ilustradas as estruturas químicas da amilose e amilopectina.

A cristalinidade dos grânulos de amido é atribuída prin-

Autor para correspondência: Luiz H. C. Mattoso, Embrapa Instrumentação Agropecuária, Caixa Postal 741, CEP: 13560-970, São Carlos, SP. E-mail: mattoso@cnpdia.embrapa.br 

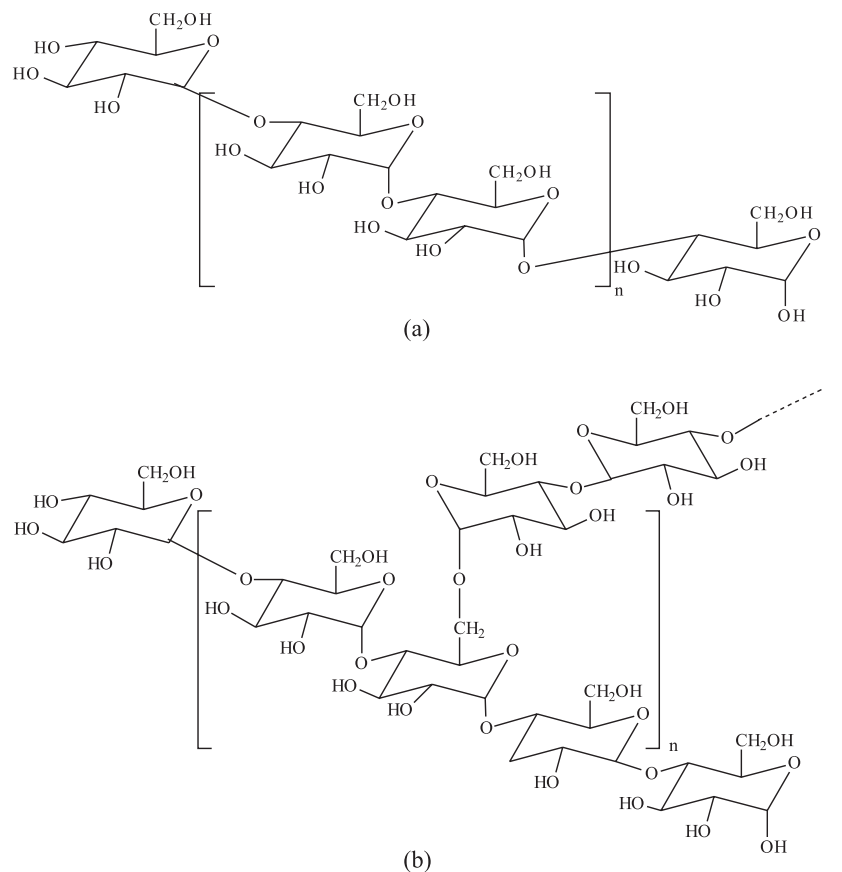

Figura 1. Estrutura química da amilose (a) e amilopectina (b).

cipalmente à amilopectina e não a amilose, que embora seja linear, apresenta uma conformação que dificulta sua associação regular com outras cadeias. $\mathrm{O}$ amido nativo pode ser classificado em três tipos de estruturas cristalinas a partir das diferenças dos difratogramas de raios-X: amidos de cereais como tipo "A", amidos de tubérculos como tipo "B" e amidos de vagens como tipo "C", uma mistura de "A" e "B ${ }^{[6]}$.

Para se obter o amido termoplástico é necessário destruir a estrutura semicristalina original dos grânulos. Para isso, o amido nativo deve ser aquecido na presença de um plastificante, como água ou glicerol, em temperaturas de 90 a $180^{\circ} \mathrm{C}$. Sob efeito de forças de cisalhamento, ele funde obtendo-se um material amorfo, o qual é denominado amido termoplástico (TPS) ou amido desestruturado ${ }^{[6]}$. O processo de desestruturação ou plastificação pode ser realizado em equipamentos convencionais de processamento de polímeros, como extrusoras, injetoras, cilindros, misturadores intensivos, $\operatorname{etc}^{[7]}$.

Durante o resfriamento, após o processamento ou quando o amido termoplástico é armazenado, ocorre a formação de estruturas cristalinas devido à recristalização da amilopectina e cristalização da amilose, apesar de essa última não apresentar cristalinidade em seu estado nativo. A tendência do amido termoplástico à cristalização afeta diretamente suas propriedades ${ }^{[7]}$. Nesse sentido, muitas pesquisas têm sido realizadas para entender melhor a relação entre a estrutura e propriedades do amido termoplástico com objetivo de ampliar a sua utilização ${ }^{[7-9]}$. Neste trabalho, dois tipos de amido derivados do milho com diferentes proporções amilose/ amilopectina (amido regular com aproximadamente $72 \%$ de amilopectina e amido ceroso com aproximadamente 100\% de amilopectina) foram processados usando glicerol como plastificante em um misturador intensivo. Os amidos termoplásticos foram caracterizados por ensaios de absorção de água, difração de raios- $X$, ensaios de tração e ensaios dinâmico-mecânicos.

\section{Experimental}

\section{Materiais}

Foram utilizados amidos derivados do milho com diferentes proporções amilose/amilopectina, doados pela Corn Products do Brasil. Amido regular com aproximadamente $28 \%$ de amilose e $72 \%$ de amilopectina, nome comercial amisol 3408, e amido ceroso, "waxy maize", com aproximadamente $100 \%$ de amilopectina, nome comercial amidex 4001.

\section{Preparação do amido termoplástico}

Foram preparadas misturas de amido/glicerol na proporção 70/30 (em massa). Essas misturas foram processadas em um misturador interno acoplado a um reômetro de torque Haake Rheomix 600 p a $160{ }^{\circ} \mathrm{C}$, com velocidade de rotação dos rotores de $50 \mathrm{rpm}$ e tempo de mistura de 6 minutos. Posteriormente, foi feita a moldagem por compressão a $160^{\circ} \mathrm{C}$, durante 5 minutos e pressão de 5 t. para produção de placas de $(150 \times 120 \times 2,5) \mathrm{mm}$ de dimensões. Os amidos termoplásticos com aproximadamente $72 \%$ e $100 \%$ de amilopectina foram designados de TPS1 e de TPS2, respectivamente.

\section{Caracterização dos amidos termoplásticos}

a) Absorção de umidade: as propriedades de absorção de água dos amidos termoplásticos, após o armazenamento por 2 semanas, foram determinadas de acordo com a norma ASTM E-104 ${ }^{[10]}$. Amostras de $1 \mathrm{~cm}$ de diâmetro, foram secas e posteriormente condicionadas a temperatura de $25 \pm 3{ }^{\circ} \mathrm{C}$ em ambiente com $53 \pm 2 \%$ de umidade relativa (u.r.). As amostras foram pesadas em sucessivos intervalos de tempo até atingir o equilíbrio. $\mathrm{O}$ teor de umidade foi calculado de acordo com a equação 1 :

$$
\text { Teor de Umidade }(\%)=\left(\frac{\text { massa }_{(u)}-\text { massa }_{(s)}}{m a s s a_{(s)}}\right) \times 100
$$

onde: $\operatorname{massa}_{(\mathrm{u})}$ e $\operatorname{massa}_{(\mathrm{s})}$ são, respectivamente, a massa "úmida" da amostra em sucessivos intervalos de tempo e a massa da amostra seca.

b) Difração de Raios X: foram realizadas análises por difração de raios-X dos amidos nativos na forma de pó e dos amidos termoplásticos (armazenados por 2 e 6 semanas) utilizando-se um difratômetro de raios X, marca Rigaku, operando em potência de $50 \mathrm{KV} / 100 \mathrm{~mA}$. A velocidade de varredura foi de $1^{\circ} / \mathrm{min}$ entre $3^{\circ}$ a $40^{\circ}$ (Ângulo de Bragg). O índice de cristalinidade (Xc) dos amidos termoplásticos foi determinado de acordo com a metodologia descrita por Hulleman et al. ${ }^{[11]}$

c) Ensaios de tração: os ensaios foram realizados numa máquina Instron modelo 5569 com célula de carga de $50 \mathrm{KN}$. 
Os corpos de prova dos amidos termoplásticos (condicionados por 2 semanas) foram confeccionados de acordo com a norma ASTM D 638M, tipo II ${ }^{[12]}$. Para cada tipo de material foram testados no mínimo cinco corpos de prova. As propriedades foram reportadas fazendo-se a média dos valores obtidos.

d) Análise dinâmico mecânica (DMA): amostras dos amidos termoplásticos (condicionados por 2 e 6 semanas) foram cortadas nas dimensões de aproximadamente $(46$ x 1,2 x 2,5) $\mathrm{mm}$, e submetidas a uma deformação senoidal no modo flexão em três pontos, no intervalo de -100 a $100^{\circ} \mathrm{C}$. As condições utilizadas foram: força dinâmica de 3,0 N, amplitude de deformação de $64 \mu \mathrm{m}$, freqüência de oscilação de $1 \mathrm{~Hz}$ e taxa de aquecimento de $2^{\circ} \mathrm{C} / \mathrm{min}$.

\section{Resultados e Discussão}

Durante o processamento das misturas de amido com glicerol, o torque foi registrado para se verificar a evolução da viscosidade no processo de desestruturação do amido granular. As curvas de torque em função do tempo para as misturas de amido com glicerol estão apresentadas na Figura 2. Os amidos com diferentes proporções de amilose/amilopectina apresentaram comportamentos reológicos diferentes. Observa-se que o torque desenvolvido para o amido regular, contento $72 \%$ de amilopectina, permaneceu constante em $12 \mathrm{Nm}$ após dois minutos, enquanto que o torque para o amido ceroso, contendo $100 \%$ de amilopectina, permaneceu constante em 5 $\mathrm{Nm}$. Em geral, as propriedades reológicas dos polímeros são influenciadas pela massa molar e sua distribuição, presença de ramificações nas macromoléculas, etc. Com relação à massa molar, quanto maior o seu valor, maior é a oposição ao fluxo viscoso, devido ao aumento no grau de emaranhamento e nos pontos de contato entre as cadeias. Por outro lado, quanto mais larga a distribuição de massa molar, menor a probabilidade de ocorrerem emaranhados e menor será a viscosidade. O efeito das ramificações no comportamento reológico depende do tamanho das cadeias macromoleculares. Polímeros ramificados com cadeias longas propiciam a formação de

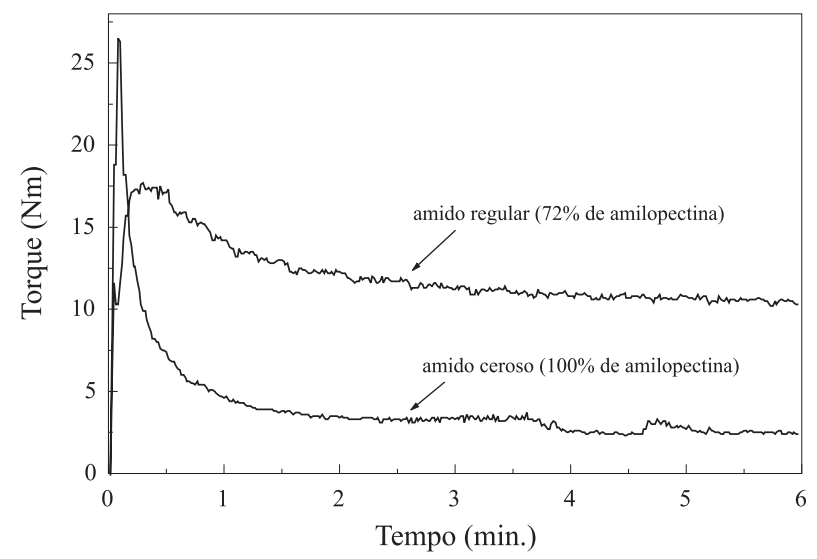

Figura 2 - Curvas de torque em função do tempo de processamento para as misturas de amido regular (72\% amilopectina) e amido ceroso (100\% de amilopectina) plastificadas com $30 \%$ de glicerol.

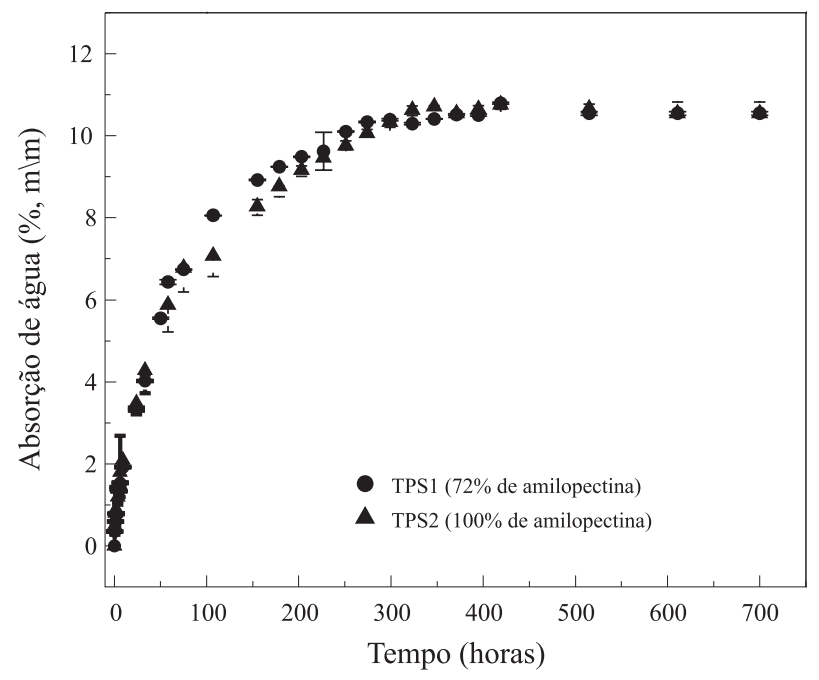

Figura 3. Curvas de absorção de água em função do tempo para o TPS1 (72\% amilopectina) e para o TPS2 (100\% de amilopectina), condicionados em ambiente de $53 \pm 2 \%$ u.r à temperatura de $25 \pm 3^{\circ} \mathrm{C}$.

emaranhados e, consequentemente, apresentam uma viscosidade maior que polímeros ramificados de cadeias curtas ${ }^{[13]}$. Apesar de o amido ceroso apresentar maior massa molar, sua viscosidade é menor que a observada para o amido regular, pois a amilopectina, seu constituinte principal, é uma macromolécula altamente ramificada, formada por curtas cadeias com aproximadamente 15 unidades de glicose, o que reduz sua habilidade para formar emaranhados. Enquanto que, as cadeias lineares de amilose são formadas de longos segmentos compostos de 40 a 60 unidades de glicose formando duplas hélices, o que propicia a formação de um grande número de emaranhados ${ }^{[14,15]} \mathrm{e}$, consequentemente, favorece um aumento na viscosidade do amido regular em relação ao amido ceroso.

Após o processamento, os amidos termoplásticos foram condicionados em ambiente de $53 \pm 2 \%$ de umidade relativa (u.r.) para determinar o tempo necessário e a quantidade máxima de água absorvida até atingir o equilíbrio, pois nesse ambiente as amostras foram condicionadas para realizar os ensaios de raios-X e mecânicos. Os resultados de absorção de umidade em função do tempo estão apresentados na Figura 3. Os dois amidos termoplásticos apresentaram comportamentos similares. Observa-se que inicialmente apresentaram velocidade de absorção alta e, após 14 dias, atingiram um patamar (absorção de equilíbrio) de aproximadamente $11 \%$. Isto se deve ao fato de que tanto a amilopectina quanto a amilose possuem uma grande quantidade de grupos hidroxilas que são responsáveis pela absorção de água.

$\mathrm{Na}$ Figura $4 \mathrm{a}$ estão apresentados os difratogramas de raios-X das amostras de amido na forma de pó. Os amidos, na forma nativa, apresentaram o mesmo padrão cristalino com picos de difração correspondente ao ângulo de Bragg $(2 \theta)$ em $15^{\circ}, 18^{\circ}$ e $23^{\circ}$, os quais são característicos do tipo A.

$\mathrm{Na}$ Figura $4 \mathrm{~b}$ estão apresentados os difratogramas de raios-X dos amidos termoplásticos após o processamento e armazenamento. Os dados de índice de cristalinidade foram calculados a partir do difratogramas de raios X e estão mos- 

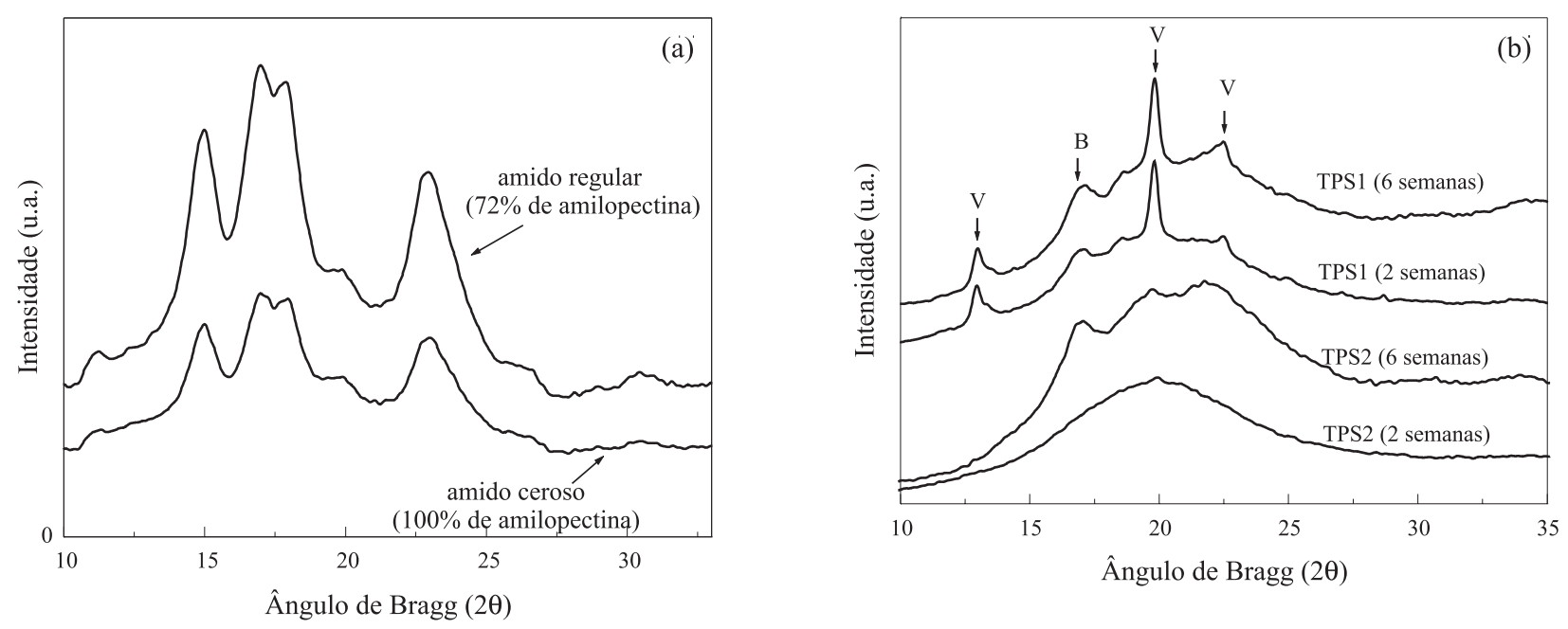

Figura 4 - Difratogramas de raios X obtidos para o TPS1 (72\% amilopectina) e TPS2 (100\% de amilopectina), na forma nativa (a) e para os amidos termoplásticos contendo $30 \%$ de glicerol (b), condicionados durante 2 e 6 semanas em ambiente com $53 \pm 2 \%$ u.r. a $25 \pm 3{ }^{\circ} \mathrm{C}$.

trados na Tabela 1. Após 2 semanas de armazenamento, foi verificado que o TPS1, contendo $72 \%$ de amilopectina, apresentou estruturas cristalinas, com picos de difração corres-

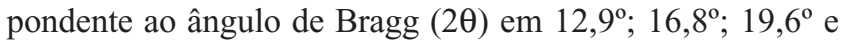
$22,4^{\circ}$; enquanto que o TPS2, contendo $100 \%$ de amilopectina, apresentou estrutura amorfa. Após 6 semanas ocorreu um aumento da cristalinidade do TPS1 e ocorreu o aparecimento de picos relativos a estruturas cristalinas em $16,8^{\circ}$ e $19,6^{\circ}$

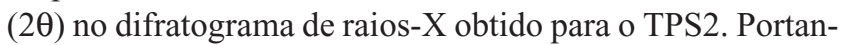
to, o amido contendo maior quantidade de amilose apresentou maior facilidade em cristalizar-se. Apesar da amilose encontrar-se no estado amorfo no amido granular e a cristalinidade dos grânulos ser atribuída amilopectina ${ }^{[6]}$, no amido termoplástico a amilose cristaliza-se rapidamente em estruturas denominadas do tipo $\mathrm{B}$ e $\mathrm{V}^{[8]}$. Os complexos do tipo V são formados pela cristalização da amilose com lipídios, com máximos no difratograma de raios $\mathrm{X}$ em aproximadamente $12,6^{\circ}, 13,2^{\circ}, 19,4^{\circ}$ e $20,6^{\circ}(2 \theta) \mathrm{em}^{[8]}$. A estrutura cristalina do tipo $\mathrm{B}$, com máximo característico em $16,8^{\circ}$ (20), era associada exclusivamente à cristalização da amilose devido à sua estrutura linear ${ }^{[11]}$. No entanto, estudos mais recentes ${ }^{[8,16]}$ mostraram que a amilopectina cristaliza-se também no tipo $\mathrm{B}$, com uma velocidade menor que a amilose. van Soest e Esser ${ }^{[8]}$ observaram que estruturas cristalinas do tipo $\mathrm{V}$ foram formadas somente pela amilose, diretamente após o processamento, enquanto que o tipo $\mathrm{B}$ de cristalinidade foi formado nos materiais ricos em amilose e também no amido contendo $100 \%$ de amilopectina, após 35 semanas de armazenamento em ambiente com $65 \%$ u.r. Após 6 semanas o TPS1 e o TPS2 apresentaram estruturas cristalinas do tipo $\mathrm{B}$ e $\mathrm{V}$, porém em quantidades diferentes. Essas diferenças ocorrem porque a amilose possui uma cinética de cristalização maior que a amilopectina, devido a sua estrutura linear ${ }^{[11]}$. Portanto, a formação das estruturas cristalinas no amido termoplástico depende da razão amilose/amilopectina e das condições de armazenamento como tempo, temperatura e umidade.

Na Figura 5 estão apresentadas as curvas de tensão-deformação obtidas através de ensaios de tração para os amidos termoplásticos, após duas semanas de armazenamento. Os valores médios do módulo de elasticidade $(\mathrm{E})$, resistência à tração na ruptura $\left(\sigma_{\mathrm{r}}\right)$ e deformação na ruptura $\left(\varepsilon_{\mathrm{r}}\right)$ estão apresentados na Tabela 2. O TPS1 apresentou maior valor de tensão na ruptura e menor deformação (Tabela 2), caracterizandose como um material mais rígido que o TPS2. Essas diferenças no comportamento mecânico dos amidos com diferentes proporções de amilose/amilopectina podem ser explicadas pelo efeito da cristalinidade formada após o processamento e armazenamento dos amidos, ou seja, a regularidade da molécula de amilose proporciona a formação de regiões cristalinas no TPS1 e, conjuntamente com maior número de pontos de contato, contribui para um comportamento semelhante aos

Tabela 1. Índice de cristalinidade (Xc) para o TPS1 e para o TPS2 calculado a partir dos difratogramas de raios X, após 2 e 6 semanas de armazenamento.

Índice de cristalinidade $(\mathrm{Xc})$

Ângulo de Bragg, $2 \theta$

\begin{tabular}{c|cc|cc|cc|cc} 
Material & \multicolumn{2}{|c|}{$\mathbf{1 2 , 9}^{\mathbf{0}}$} & \multicolumn{2}{c|}{$\mathbf{1 6 , 8}^{\mathbf{0}}$} & \multicolumn{2}{c|}{$\mathbf{1 9 , 6}^{\mathbf{0}}$} & \multicolumn{2}{c}{$\mathbf{2 2 , 4}^{\mathbf{0}}$} \\
\cline { 2 - 9 } & 2 semanas & $\mathbf{6}$ semanas & 2 semanas & 6 semanas & 2 semanas & $\mathbf{6}$ semanas & 2 semanas & 6 semanas \\
\cline { 2 - 9 } TPS1 & 0,37 & 0,37 & 0,13 & 0,18 & 0,31 & 0,31 & 0,10 & 0,16 \\
TPS2 & 0 & 0 & 0 & 0,13 & 0 & 0,05 & 0 & 0 \\
\hline
\end{tabular}




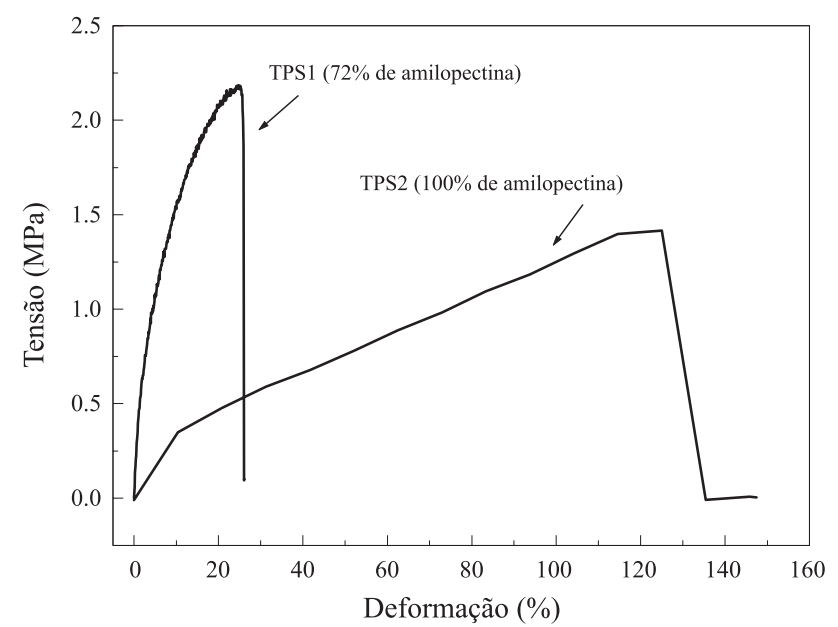

Figura 5. Curva tensão-deformação dos amidos termoplásticos: TPS1 (72\% de amilopectina) e TPS2 ( $100 \%$ de amilopectina), condicionados durante 2 semanas em ambiente com $53 \pm 2 \%$ u.r. a temperatura de $25 \pm 3{ }^{\circ} \mathrm{C}$.

polímeros semicristalinos convencionais, i.e, maior módulo elástico, maior tensão de ruptura e menor deformação na ruptura. É conhecido na literatura que a formação de pequenas quantidades de cristalinidade do tipo B aumenta a rigidez e a resistência à tração e diminui a deformação do amido termoplástico ${ }^{[15]}$. Portanto, os maiores valores de $\mathrm{E}$ e de $\sigma_{\mathrm{r}} \mathrm{e}$ o menor valor de $\varepsilon$ para o TPS1 estão relacionados com a presença de cristalinidade, como observado nos difratogramas de raios-X (Figura $4 b$ ).

O TPS2, por outro lado, apresentou menor valor de tensão na ruptura e maior deformação na ruptura devido as macromoléculas de amilopectina terem apresentado estrutura totalmente amorfa (após 2 semanas de armazenamento) e também, por possuírem um número de ramificações grande e massa molar maior que a da amilose, causando um aumento na flexibilidade e favorecendo um aumento da deformação na ruptura do TPS2 em relação ao TPS1.

O comportamento dinâmico-mecânico dos amidos termoplásticos, após 2 e 6 semanas de armazenamento, está apresentado na Figura 6, por meio do módulo de armazenamento (E') e do amortecimento ( $\tan \delta$ ) em função da temperatura.

Observa-se que à temperaturas acima de $10{ }^{\circ} \mathrm{C}$, o módulo de amortecimento (E') aumentou com o aumento da cristalinidade dos amidos termoplástico. O TPS2, o qual exibiu estrutura amorfa (após 2 semanas de condicionamento) apresentou menores valores de E', sendo que a formação de pequenas quantidades de cristalinidade causou um aumento

Tabela 2. Módulo de elasticidade (E) tensão na ruptura $(\sigma)$, alongamento na ruptura $(\varepsilon)$ dos amidos termoplásticos: TPS1 (72\% de amilopectina) e TPS2 (100\% de amilopectina), condicionados durante 2 e 6 semanas em ambiente com $53 \pm 2 \%$ u.r. a temperatura de $25 \pm 3^{\circ} \mathrm{C}$.

\begin{tabular}{cccc}
\hline Material & E(MPa) & $\begin{array}{c}\boldsymbol{\sigma}_{\mathrm{r}} \\
(\mathbf{M P a})\end{array}$ & $\begin{array}{c}\boldsymbol{\varepsilon}_{\mathrm{r}} \\
(\boldsymbol{\%})\end{array}$ \\
\hline TPS1 & $38,6 \pm 0,1$ & $2,1 \pm 0,1$ & $26,7 \pm 3,9$ \\
TPS2 & $9,0 \pm 0,4$ & $1,7 \pm 0,3$ & $83,5 \pm 11,9$ \\
\hline
\end{tabular}
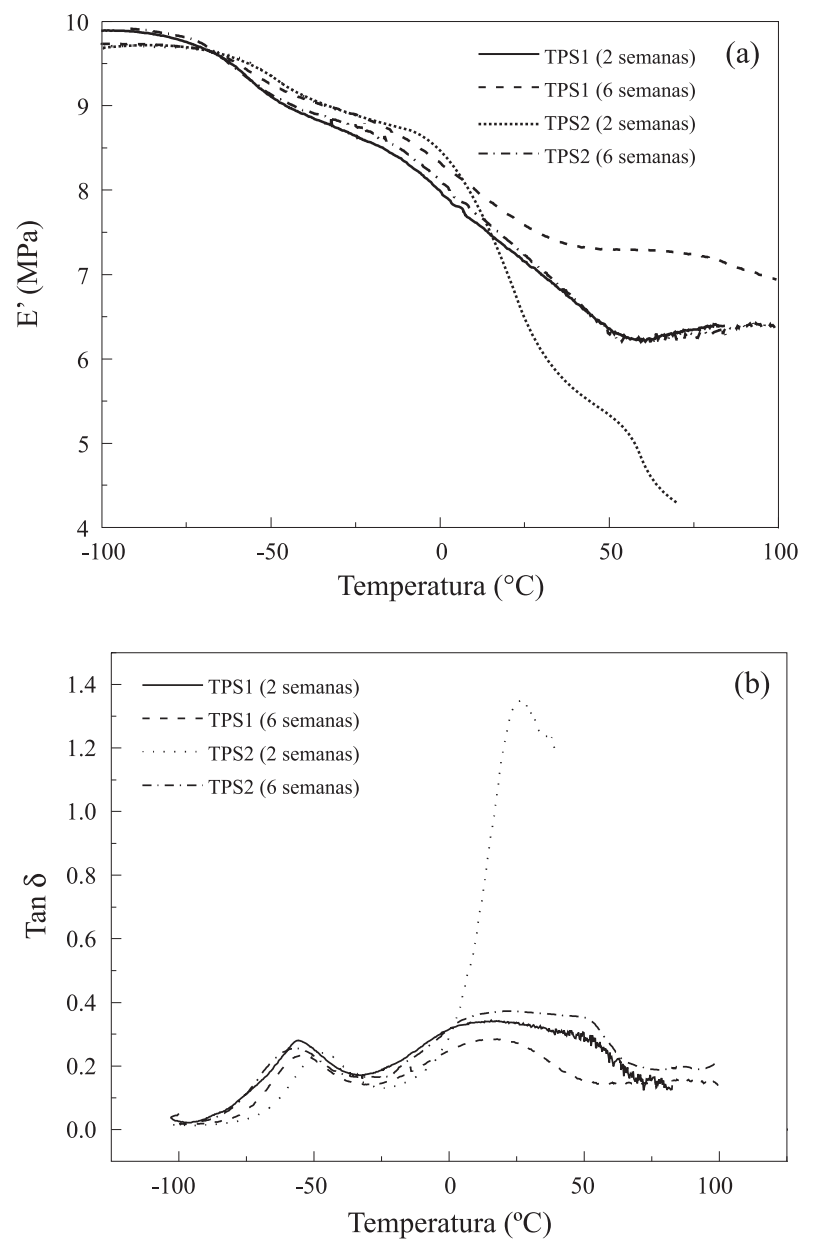

Figura 6 - Curvas de DMA para os amidos termoplásticos, TPS1 (72\% de amilopectina) e TPS2 (100\% de amilopectina), condicionados durante 2 e 6 semanas em ambiente com $53 \pm 2 \%$ u.r. a temperatura de $25 \pm 3{ }^{\circ} \mathrm{C}$, (a) módulo de armazenamento (E'), (b) amortecimento $(\tan \delta)$,

significativo no módulo de armazenamento após 6 semanas. Para o TPS1 o aumento da cristalinidade também levou um aumento no módulo de armazenamento. Como o módulo de armazenamento é uma medida da rigidez do sistema, aumentando-se a cristalinidade do material, consequentemente, há um aumento no valor do módulo de armazenamento ${ }^{[17]}$.

Duas transições foram observadas em temperaturas próximas para os amidos, caracterizadas por um máximo nas curvas de amortecimento $(\tan \delta$ ) associado a uma diminuição de E'. A primeira é uma transição secundária e ocorre em temperaturas próximas para os dois amidos, em torno de $-55^{\circ} \mathrm{C}$, a qual é atribuída a domínios ricos em glicerol ${ }^{[17]}$. A segunda transição é referente à $\mathrm{Tg}$ do amido termoplástico, sendo que sua intensidade foi reduzida com o aumento da cristalinidade, devido a diminuição da mobilidade dos segmentos das macromoléculas em função do aumento e/ou formação de estruturas cristalinas.

\section{Conclusões}

O amido regular contento aproximadamente $72 \%$ de amilopectina apresentou maior viscosidade durante o 
processamento, que foi atribuída à presença das cadeias lineares de amilose, as quais apresentaram maior entrelaçamento do que as cadeias ramificadas da amilopectina. Após o processamento e armazenamento por 6 semanas, o TPS1 apresentou maior índice de cristalinidade que o TPS2, devido a presença da amilose que possui maior velocidade de cristalização que amilopectina. A presença de estruturas cristalinas nos amidos termoplásticos melhorou a resistência mecânica do material resultando em um aumento no módulo e tensão na ruptura e diminuição do alongamento do amido termoplástico.

Esse estudo propiciou um melhor entendimento das propriedades dos amidos termoplásticos, mostrando que esses materiais podem ser empregados para a fabricação de utensílios biodegradáveis de baixa solicitação mecânica e curto tempo de uso. No entanto, suas propriedades mecânicas podem ser melhoradas pela incorporação reforços como as fibras naturais, favorecendo o desenvolvimento de um compósito com maior resistência mecânica sem, contudo afetar sua biodegradabilidade.

\section{Agradecimentos}

Os autores agradecem à Corn Product do Brasil pela doação das amostras de amido, ao Dema/UFSCar pelo uso do reômetro de torque, ao CNPq e à Fapesp pelo apoio financeiro concedido.

\section{Referências Bibliográficas}

1. Wang, X.L.; Yang, K.K.; Wang, Y.Z. - J. Macromol. Sc.Polym. 43, p.385 (2003).

2. Scott G. "Polymer and the Environment". The Royal Society of Chemistry, Letchworth,UK, cap.5, p.93 (1995).

3. Chandra, R.; Rustgi, R. - Prog. Polym. Sci., 23, p.1273 (1998).

4. Whistler, R.L.; Daniel, J.R. - "Starch”, in: Encyclopedia of chemical technology, 21, p.492, Kirk Othmer, New York (1983).
5. Coultate, T.P. - "Food: The Chemistry of its Components". (3a ed.), Royal Society of Chemistry Paperbacks, London, cap.3, p.26 (1996).

6. Blanshard, J.M.V. - "Starch granule structure and function: a physicochemical approach", in: Starch: Properties and Potentials, Galliard, T Chichester, John-Wiley, New York, cap.2, p.16 (1987).

7. Wiedmann, W.; Strobel, E. - Starch/Stärke, 43, p.138 (1991).

8. van Soest, J. J. G.; Esser, P. - J. Macrom. Science, 34, p.1665 (1997).

9. van Soest, J.J.G.; de Wit, D.; Vliegenthart, J.F.G. - J. App. Polym. Sci., 61, p.1927 (1996).

10. ASTM E-104-85 - "Standart pratice for maintaining constant humidity by means of aqueous solutions", Philadelphia , 11 (1996).

11. Hulleman, S.H.D.; Kalisvaart, M.G.; Jansen, F.H.P.; Feil, H.; Vliegenthart, J.F.G. - Carbohyd. Polym., 39, p. 351 (1999).

12. ASTM D-638M-96 - "Standard test for tensile properties of plastics", Philadelphia 11 (1996).

13. Han, C. D. - "Rheology in Polymer Processing", Academic Press, Londres, cap.4, p.76 (1976).

14. Della Valle, G.; Collona, P.; Patria, A. - J. Rheol., 40, p.347 (1996).

15. Della Valle, G.; Buleon, A. - J. Rheol., 42, p.507 (1998).

16. Murayama, T. "Dynamic mechanical analysis of polymeric materiaP', Elsevier Scientific Publishing Company, New York, cap. 3, p.63 (1978).

17. Lourdin, D.; Bizot, H.; Colonna, P. - J. App Polym Sci., 63, p.1047 (1997).

Enviado: 21/12/04

Reenviado: 25/06/05

Aprovado: 01/07/05 